JOURNAL EXCHANGE

\section{East and Central European Journals}

The exchange of physics journals is extremely important for east and central European countries as it provides a relatively inexpensive means to acquire foreign publications. The east and central European journals listed below have undertaken to ensure that copies of journals received from outside their respective countries will be made available to the physics community at large (generally by keeping the journals in a centrally located and easily accessible library).

Publishers of physics journals are encouraged to initiate or extend exchange arrangements by contacting the offices listed in the table on the right. Further details can be obtained from the editors of the journals.

Editorial Offices (contacts for exchanges in ithalics)

Bulgarian Journal of Physics Physics Faculty, Sofia University, J. Bouchier Blvd. 5, B-1126 Sofia Fax $+359-2-689085$

Union of Physicists in Bulgaria Blvd. J. Bourchier 5,

BG-1126 Sofia Fax +359-2-68 9085

\section{Czechoslovak Journal of Physics}

Institute of Physics, Academy of Science

of the Czech Republic, Na Slovance 2 .

CZ-180 40 Prague 8 Fax +42-2-82 1227 Email cjp@fzu.cz

Proceedings of the Estonian Academy of Science

Estonian Academy of Science, Estonia pst. 7.

EE-0100 Tallinn

Fax $+372-0142-527901$

Estonian Academy of Science Library,

10 Rvala Ave., EE-0100 Tallinn

Fizika A, B Fac. of Natural Sciences \& Maths, POB 162 , HR-41000 Zagreb Fax +385-1-432180

Email ilakovac@phy.hr

http://www.hfd.hr/hfd/publ/fiza.html

Acta Physica Hungarica: Heavy lon Physics

Department of Theoretical Physics,

Debrecen University, POB 5

H-4010 Debrecen Fax +36-52-41 6181

http://www.atomki.hu/debrecen/hiph/hiph.html
Lithuanian Journal of Physics

Academy of Science of Lithunia, Gedimino pz. 3 , LT-2600 Vilnius

Lithunian Physical Society, A. Gostauto 12

LT-2600 Vilnius Fax $+370-2-618464$

Acta Physica Polonica Institute of Physics, Polish Academy of Sciences, Al. Lotników 32/46, PL-02-668 Warsaw

Fax +48-22-430926 http://info.ifpan.edu.pl/

Romanian Journal of Physics POB MG-6, R-Bucharest/Magurele Fax + 40-1-31222 47

Romanian Academy Library, Calea Victoriei 131, R-Bucharest

\section{Obzornik za Matematiko in Fiziko}

Society of Mathematicians, Physicists \& Astronomers of Slovenia (SMPAS), POB 64

SI-61111 Ljubjana Fax +386-61-217281

Acta Physica Slovaca Institute of Physics, Slovak Academy of Sciences, Dúbravaská cesta 9 SK-84228 Bratislava

Fax +42-7-376085 Email aps@savba.sk

Balkan Physics Letters Physics Department, Istanbul University, TR-34459 Vezneciler

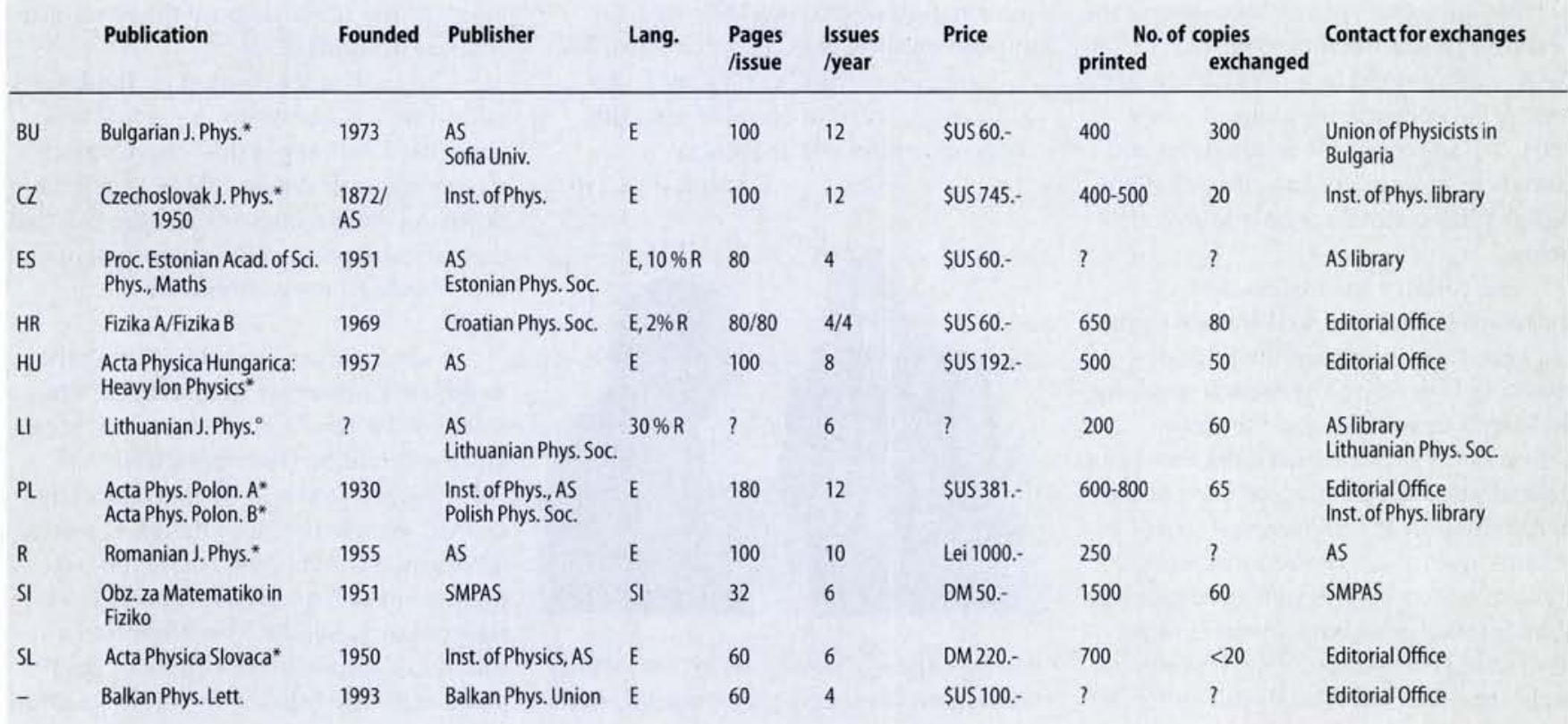

*EPS Recognized Journal, ' English translation available, Languages: E- English; R-Russian, AS: Academy of Science, SMPAS: Society of Mathematicians, Physicists and Astronomers of Slovenia

\section{EC Documents}

\section{Programme Calls}

The full texts of the latest ( 15 December 1995) three-monthly advance notices and calls for proposal and expressions of interest in a number of European Union 4th Framework programmes can be downloaded from the European Commission's (EC) CORDIS Document Library. Calls normally have a three-month response time. Included are (http://www.cordis.lu/): - ESPRIT, Training \& Mobility of Researchers, BRITE/EURAM, Stan- dards, Meas.\& Testing (calls); - JOULE/THERMIE non-nuclear energies (adv. notice of call); - INNOVATION networks of organizations for promoting energy technologies and for disseminating and optimizing the results of research and technological development (RTD) activities (calls); - ENV ${ }_{2} \mathrm{C}$ study courses and training grants for RTD in environment and climate (call);

- INCO list of persons and organizations to assist the EC in the RTD programme, including cooperation with third countries and international organizations (call for expressions of interest);

-TSER list of potential contractors to carry out tasks for the European Technology Assessment Network (call for expressions of interest).

\section{Publications}

- European Research - Guide to the Preparation of a Successful Proposal Orders (LIT 29000 excl. postage): APRE (Rome); fax: +39-6-323 2618 - PHARE Address Book giving key contacts in the eleven east and central European PHARE countries. Contact: PHARE Info. Unit, DG I, , EC, 200, r. de la Loi, B-1049. fax: +32-2-299 1717
- TACIS Contract Information

Updates and the Management Guide to the Organization of the TACIS Programme detailing TACIS programmes (for the CIS and Mongolia) in which the EC is organizing restricted invitations to tender. Contact: TACIS Info. Unit, DG I, EC, 200, r. de la Loi, B-1049. fax: +32-2-231 0441

- European Course Credit Transfer system Users Guide to assist educational establishments integrate into the scheme in order to guarantee academic recognition of studies abroad. Contact: SOCRATES, 70, r. Montoyer, B-1040 Brussels. 